\title{
Importance and Descriptiveness of Self-Aspects: A Cross-Cultural Comparison
}

\author{
Sandra Carpenter \\ The University of Alabama in Huntsville \\ Zahide Karakitapoḡlu-Aygün \\ Bilkent University, Turkey
}

This study investigated self-concept similarities and differences among Turkish and American (Mexican American and White) university students. The descriptiveness of self-attributes was measured in three domains (independent self, relational self, and other-focused or traditional self). In addition, the importance of personal, social, and collective selves was identified for each culture group. In terms of importance of self, the cultural groups showed more similarities than differences, emphasizing personal identity the most, followed by social and collective identity orientations. The results also suggested similarities across the cultural groups in descriptiveness of self-aspects, whereby relational attributes were rated as more selfdescriptive than independent and other-focused or traditional aspects. Despite these similarities, our results suggested that importance and descriptiveness ratings do not show the same pattern. The results are discussed in terms of self-schemas and the association between aspects of the self that are important and descriptive of the self.

Keywords: self-description; identity orientation; importance and descriptiveness of self; self-schemas

Cross-Cultural Research, Vol. 39 No. 3, August 2005 293-321

DOI: $10.1177 / 1069397104273989$

(C) 2005 Sage Publications 
Several recent studies of the self have focused on the variations of the self across cultures, primarily investigating the relation of individualism-collectivism to self-conceptions (Bond \& Cheung, 1983; Brewer \& Gardner, 1996; Cousins, 1989; Markus \& Kitayama, 1991; Oyserman, 1993; Rhee, Uleman, Lee, \& Roman, 1995; Singelis, 1994; Uleman, Rhee, Bardoliwalla, Semin, \& Toyama, 2000). A variety of studies have also shown systematic differences in self-concept as a function of gender (Cross, Bacon, \& Morris, 2000; Cross \& Madson, 1997; Gabriel \& Gardner, 1999; Gilligan, 1982). A third set of studies examined the interaction between gender and culture on self-representations (Dhawan, Roseman, Naidu, Thapa, \& Rettek, 1995; Driver \& Driver, 1983; Kashima \& Hardie, 2000; Kashima et al., 1995; Lykes, 1985; Watkins et al., 1998; Watkins, Mortazavi, \& Trofimova, 2000). The vast majority of these studies have examined the descriptiveness of various aspects of self across genders and cultures. We, however, extend this work by additionally investigating the importance of these aspects of the self, as a function of gender and culture. The convergence of the descriptiveness and importance of particular aspects of the self-concept inform us with respect to the schematicity of those aspects with reference to self (i.e., self-schematicity; Markus, 1977); that is, people are considered to have self-schemas for characteristics (e.g., honesty, ambition) if the characteristics are descriptive of self and important to the self-concept. Schematicity affects all levels of social perception (e.g., attention, interpretation, memory) and thus strongly influences values and behavior. For example, people who are self-schematic for honesty will be more likely to pay attention to situations in which honesty may be relevant, will interpret their own and others' behaviors in terms of honesty, and will have good memory for honest and dishonest behaviors in themselves and others (Carpenter, 1988; Markus, 1977). In our exploration of self-schematicity across cultures, we draw from several theoretical and empirical conceptions of self, providing a broad base for identifying similarities and differences between groups. Our research also adds to this body of research by focusing on a country that is relatively underrepresented in the literature, Turkey.

Most related studies in Turkey have investigated general tendencies, attitudes, and values of Turkish people as a function of individualism-collectivism (Göregenli, 1997; Imamoḡlu \& Karakitapoḡlu-Aygün, 1999; Karakitapoḡlu-Aygün \& Imamoḡlu, 2002) but have lacked a systematic study of self-conceptions. Thus, 
empirical research is needed to shed light on the issue of self among Turkish people in line with recent cultural approaches to the self in the literature. Turkey has been undergoing a very rapid social transition since the 1980s. It is likely that the transformations in values and self-perceptions of individuals during such a change would be articulated in one's self-conceptions (KarakitapoḡluAygün, 2004).

\section{CONCEPTIONS OF SELF}

Markus and Kitayama (1991) proposed the distinction between different conceptions of self, such that an individual would be would be classified as having either an independent or interdependent self-construal. The independent construal of self is defined as summation of individual attributes, values, attitudes, and abilities that differentiate one from other. The interdependent construal of self is characterized by social roles, relationships, and connectedness of human beings to each other.

A distinction has been made among individual, relational, and collective aspects of the self (Brewer \& Gardner, 1996; Kashima \& Hardie, 2000; Kashima, Kashima, \& Aldridge, 2001; Kashima et al., 1995; Sedikides \& Brewer, 2001), which presumes that individuals have independent and interdependent selves that vary in priority. The individual self is defined by the unique characteristics that differentiate the individual from his or her social environment. The relational self is generally defined as the interpersonal aspects of the self that are crucial in forming and maintaining relationships with others. Finally, in this model, the collective self is defined as belongingness to larger social in-groups (e.g., ethnic, racial, religious, national group). Furthermore, Cross and her colleagues (2000) more fully developed the notion of the relational self, which they term the relational-interdependent self. This construal is determined by the extent to which individuals conceptualize themselves in terms of their relationships with close others.

Cheek (1989) made somewhat similar distinctions between personal, social, and collective identity orientations and studied the importance of these identity orientations. He defined personal identity as private self-conceptions and subjective feelings, and social identity as public image and social roles and relationships. Finally, he defined collective identity as membership in and identification 
with different groups and collectives, such as religious, national, or ethnic groups. Each of these conceptions of self-the personal or individual, the social, and the collective - theoretically coexists in a single individual. Within an individual, however, these different aspects would vary in their descriptiveness and importance.

\section{MEASUREMENT OF SELF-REPRESENTATIONS}

Researchers have designed a few questionnaire measures to identify the descriptiveness of various aspects of the self: the relationalinterdependent self (Cross et al., 2000) and independent versus interdependent self-construals (Singelis, 1994). However, crosscultural analyses of self-concept more frequently use the Twenty Statements Test (TST; e.g., Bochner, 1994; Bond \& Cheung, 1983; Cousins, 1989; Dhawan et al., 1995; Driver \& Driver, 1983; Ip \& Bond, 1995; Rhee et al., 1995) to elicit information about individuals' self-representations. In this measure, participants use a free format to describe themselves, and then their descriptors are classified with respect to a variety of categories (e.g., roles, independent attributes, qualified characteristics). Such a measure taps into characteristics that are most accessible in the self-system (see Fiske \& Taylor, 1991, for a summary of accessibility). Constructs that are accessible are those that have been utilized (e.g., for interpretation of behaviors, for self-evaluation) most recently or those that are used very frequently. Highly accessible attributes are likely to be descriptive; however, they are not necessarily the characteristics that are most self-descriptive, nor those that are most important to the self-concept. Thus, although the above studies provided a rich understanding by identifying independent-interdependent or relational elements of self within a cultural perspective, one consistent lack of concern in these studies was the distinction between descriptiveness and importance of self-definitions. ${ }^{1}$

Markus (1977) differentiated between these two features of self. She designated people as schematic for an attribute if they rated a characteristic as descriptive and important. Thus, the importance and descriptiveness of any particular self-related attribute need not co-occur. For example, a woman who considers herself as average in attractiveness (i.e., giving herself a moderate rating for that attribute) may rate attractiveness as a very important characteristic in her self-concept if she aspires to be a great beauty. In addition, conversely, a woman who is very attractive may not consider 
her physical appearance to be a central and important aspect of her self-concept. Thus, we contend that a more complete understanding of the self-concept requires an analysis of the descriptiveness and importance of various characteristics of the self.

The current study was designed to explore the relationship between the importance and descriptiveness of several aspects of self in different sociocultural contexts. In our research, we used Cheek's U.S.-derived measure of the importance of these three identities (personal, social, and collective), the Aspects of Identity Questionnaire (AIQ-IIIx; Cheek, Trapp, Chen, \& Underwood, 1994), to quantify and compare the importance dimension of self-attributes across cultures. To measure descriptiveness, the Turkish coauthor of the current article created a measure that focused on the independent, relational, and other-focused or traditional aspects of the self based on a previous self-description scale (Karakitapoḡlu-Aygün, 2004). The independent aspect was measured in terms of the descriptiveness of several personal traits emphasizing individuality, openness, and differentiation from others (e.g., curious) and was expected to show some convergence with the personal identity measured by the AIQ. The relational aspect was measured in terms of interpersonal traits emphasizing maintaining relationships with others (e.g., sacrificing, helpful). Finally, the other-focused or traditional aspect was measured in terms of attention to others' expectations (e.g., traditional, influenced by others' goals). As a matter of fact, the last two dimensions include relational elements-one being more directed toward others (helpful, friendly) and the other being more influenced by others. However, the other-focused or traditional domain refers to a more conservative and traditional aspect of the self, involving social approval, social expectations, traditionalism, and inflexibility in thoughts. Thus, both of these two self-aspects were expected to be associated with social and collective identity orientations measured by the AIQ. These trait items, although admittedly descriptive only of individual traits, reflect the differences between independent and interdependent self-concepts documented in previous literature (Bochner, 1994; Bond \& Cheung, 1983; Cousins, 1989; Dhawan et al., 1995; Driver \& Driver, 1983; Ip \& Bond, 1995; Rhee et al., 1995) ${ }^{2}$; that is, researchers who use the TST typically categorized personal traits as independent, interdependent or relational, or collective (among other categories). We are maintaining that theoretical and methodological perspective in this work by having 
participants respond to traits that are exemplars of independent, relational, and other-focused or traditional.

The current study aimed to contribute to the literature on self in two ways: (a) by measuring importance and descriptiveness of selfdefinitions and (b) by comparing the Turkish and American (White and Mexican American) students in their components of selfdefinition. Second, we aimed to explore how these aspects of the self differ among women and men across these cultural contexts. Below, we consider the related literature on self, culture, and gender, and formulate our hypotheses.

\section{CULTURE AND THE SELF}

The extent to which the self-concept is defined as independentinterdependent (or as having extensive personal, social, otherfocused, or collective components) depends on the culture within which individuals live. In general, individuals from Western, individualistic cultures have been shown to have independent, autonomous, and private self-conceptions emphasizing inner attributes, personal preferences and abilities. On the other hand, individuals from non-Western, collectivistic cultures tend to have interdependent, relational and collectivist construals of self that emphasize social roles and memberships to groups (Bond \& Cheung, 1983; Brewer \& Gardner, 1996; Kashima et al., 1995; Markus \& Kitayama, 1991; Oyserman, 1993; Rhee et al., 1995; Triandis, 1989; Uleman et al., 2000). In line with the bipolar individualistic-collectivist dimension, the American culture has been defined as an individualistic culture and Turkey as a fundamentally collectivistic culture.

The traditional Turkish sociocultural context has been characterized by emphasis on interpersonal relationships and close ties with family and relatives (Güneri, Sümer, \& Yıldırım, 1999; Imamoḡlu, 1987; Kaḡıtçııaşı, 1990, 1996b). Family, group membership, and social roles are among the major influences in defining one's self and identity within a "fused and undifferentiated system of relationships" (Fișek, 1984, p. 310). However, more recent research showed that the sociocultural context in modern urban Turkey is conducive to independent and relational construals of self and identity. Because of free market economy and trends toward liberalization after the 1980s, Turkey has been undergoing a very rapid social change. Therefore, Turkish people tend to express more individualism in their attitudes and values especially after the 
1990s (Çileli, 2000; Göregenli, 1997; Imamoḡlu, 1987; Kaḡıtçıbașı, 1990, 1996a, 1996b). For example, Karakitapoḡlu-Aygün and Imamoḡlu (2002; Imamoḡlu \& Karakitapoḡlu-Aygün, 1999) showed that individualistic and relational values are among the most emphasized value types in the late 1990s. These studies also found that the strength of traditional collectivistic values restricting individual autonomy tends to decrease with social change, although traditional benevolence values are still important. In sum, the recent research in Turkey refers to a coexistence of traditional relatedness tendencies with new individualistic ones: "balanced differentiation-integration" or "interrelated-individuation" (Imamoḡlu, 1998), "related autonomy" (Karadayı, 1998), and "emotional interdependence" (Kaḡitçıbașı, 1990, 1996a, 1996b). Hence, especially modern urban Turkish youth seem to hold and combine independent and relational elements in their self-definitions.

In line with these findings, American and Turkish university students in the current study might not be expected to differ in individual and relational aspects of the self but to differ in otherfocused or traditional or collectivistic ones. More specifically, Turkish respondents were expected to rate other-focused or traditional and collectivistic aspects of the self as more self-descriptive and more important than the White respondents. This hypothesis is in line with Hofstede's (1980) assessment of the United States as a more individualistic culture than Turkey (country ratings on collectivism of 37 and 91, respectively). The strength of the individualistic perspective in the United States, however, varies by ethnicity and by region of the country (Vandello \& Cohen, 1999). Our U.S. sample, with respect to participants completing the measure of identity importance (AIQ), consists of students from a university on the border of Mexico and students from a university in the Southeast of the United States. Ratings of collectivism for these states were similar in Vandello and Cohen's (1999) analysis (i.e., New Mexico $=51$, Texas $=58$, and Alabama $=57$ ). Thus, the selfconcepts of these students might be expected to be similar, with respect to collectivism.

The U.S. students described in the current study, however, also diverged in ethnicity. The Southeastern sample reported here was of European heritage, whereas the Southwestern sample was of Hispanic origin. A meta-analysis by Oyserman, Coon, and Kemmelmeier (2002) and research by Gaines and colleagues (1997) have shown Mexican Americans to be more collective than 
Whites within the United States. Mexicans' self-concept is derived in a context in which value is placed on cohesion, cooperation, family, and unity. Relationships are reciprocal, long lasting, and accommodative, such that self-modification is normative (DiazLoving \& Draguns, 1999). Mexicans emphasize simpatía, a tendency to promote easy, smooth social relationships (Triandis, Marín, Lisansky, \& Betancourt, 1984). Thus, Mexicans attend to their influence on others, as well as others' influence of themselves; that is, the other-focused or traditional self should be salient and important.

In support of this position, Trafimow and Finlay (2001) found that although Mexican Americans and Whites ranked personal attributes as more important than group attributes, (a) Whites ranked personal attributes as more important than did Mexican Americans and (b) Mexican Americans ranked group attributes a more important than did Whites. Similarly, research by Cheek et al. (1994) showed that participants with European, Hispanic, and Asian heritage showed similarity in their ratings of the importance of their personal and social identities. Participants with European heritage, however, rated their collective identities as less important than did participants with Asian or Hispanic heritage. Within the U.S. sample, then, we expected that Whites and Mexican Americans would indicate the personal self to have the greatest importance but that Mexican Americans would place greater importance on the collective and other-focused or traditional selves than would the White subsample.

Therefore, our first hypothesis was that the social and collective selves, as well as the other-focused or traditional self, would be more important to and descriptive of Mexican Americans and Turkish students than White students. Second, as the personal self has been shown to be most important to participants of various ethnicities and cultures, we expected minimal differences in the importance or descriptiveness of the personal or independent self across our samples (Hypothesis 2). Third, we expected small crosscultural differences (Hypothesis 3) regarding the relational aspect of the self because being relational and feelings of belongingness to others seem to be a universal human need (Baumeister \& Leary, 1995; Guisinger \& Blatt, 1994; Imamoḡlu, 1998; Kaḡıtçıbaşı, 1996a, 1996b; Tice \& Baumeister, 2001).

We were also interested in identifying whether self-schemas (Markus, 1977) show systematic patterns of variation within 
cultures; that is, do ratings of importance and descriptiveness covary across individuals within cultures? Individuals may report differences in the degree to which they "fit" the cultural model of personality or salient values relevant to self-aspects. They may use the culturally valued characteristics as a yardstick by which to measure their own attributes, such that significant individual variation occurs for the most salient characteristics. If this is the case, we should find the strongest correlations between the importance and descriptiveness ratings of the culturally valued characteristics. These correlations should be accompanied by mean ratings of both characteristics that approximate the center of the rating scale. Thus, Hypothesis 4 was that Whites would show schematic patterns (correlations) for the personal identity and independent descriptiveness ratings and that Turks would show selfschematic patterns of ratings for social identity and descriptiveness of relational self-aspects, as well as for collective identity and the descriptiveness of other-focused or traditional self-aspects.

\section{GENDER AND THE SELF}

Gender roles also may play a crucial role in self-definitions. Research has shown that men are more likely to show independence, emphasizing autonomy, separateness, and personal agency (see Cross \& Madson, 1997, for a review; Gabriel \& Gardner, 1999; Gilligan, 1982). Women, on the other hand, are more likely to have interdependent and relational construals of self than men, emphasizing relatedness and close ties with others. For example, Gabriel and Gardner (1999) found that women describe themselves as more relational, have higher scores on relational self-construal, show more emotional experiences in association with relationships, and pay more attention to information about the relationships. Thus, studies have illustrated that gendered socialization encourages women toward a more relational self and men toward more independent self. In Hypothesis 5, we therefore predicted that women would indicate that their relational, other-focused or traditional, and collective selves are more self-descriptive and important than would men. With respect to self-schematicity, women may therefore be self-schematic for relational and collective aspects of themselves. Alternatively, there may not be any systematic patterns related to gender because previous studies have shown that culture is a significantly stronger influence on 
self-concept than is gender (Dhawan et al., 1995; Driver \& Driver, 1983). Individual differences in self-schematicity might, then, be expected to more closely follow culture than gender prescriptions. We explore these two possibilities in the current research.

\section{METHOD}

\section{PARTICIPANTS}

The Turkish sample consisted of 125 university students (58 men, 67 women) from various departments of Middle East Technical University, which is one of the most prestigious universities in Ankara. Ankara is an urban city and the capital of Turkey. The mean age of the sample was $20.23(S D=1.63)$. Thus, the sample can be said to represent middle-upper socioeconomic status (SES) metropolitan Turkish youth.

Students in the U.S. sample attended state universities and were members of introductory psychology courses who voluntarily chose research participation as an option for course credit. Ethnicity was determined through self-report. The Hispanic portion of the U.S. sample consisted of 71 Mexican American students (47 women and 24 men) who lived in a large city bordering Mexico. Mexican American students comprised $75 \%$ of the student body at this university and thus represent a majority (in terms of numbers) of these students. The majority of these students were bilingual, with adequate proficiency in English to take English-based college courses. The White sample consisted of 135 students (89 women and 46 men) who lived in a moderate-sized southeastern city steeped in aerospace technology. Whites constituted $72 \%$ of the student body at this university, representing a majority of these students (in terms of numbers). The mean age of the Mexican Americans was $18.99(S D=1.28)$ and was $19.92(S D=1.78)$ for the White sample.

\section{INSTRUMENTS}

Two questionnaire measures were used to elicit importance and descriptiveness ratings from the Turkish and U.S. students. The English and Turkish versions of the both scales were checked through back translations. Then, native speakers of English and 
Turkish checked for wording, accuracy, and clarity of items in both languages.

Self-descriptions. The items were designed by the Turkish coauthor to be representative of independent traits (e.g., intelligent, creative; five items), relational attributes (e.g., friendly, sharing; five items), and other-focused or traditional characteristics of self (e.g., affected by others' views, expects approval; six items). Respondents were asked to rate each description in this scale on a 6-point Likert-type scale, 1 (not at all descriptive of me) to 6 (very descriptive of me). The 6-point scale was preferred to a 5- or 7-point scale to reduce neutrality bias in the answers.

Identity orientations. Cheek et al.'s (1994) Aspects of Identity Questionnaire (AIQ-IIIx) scale was used to assess identity orientations. They conceptualized identity orientations as consisting of three subscales: personal, social, and collective. Personal Identity emphasizes the importance of personal ideas and feelings. This subscale included 10 items such as "my dreams and imagination," "my personal goals and hopes for the future," and "my emotions and feelings." Social Identity emphasizes the importance of social roles and relationships. It consists of seven items such as "my social behaviors, such as the way I act when meeting people," and "my reputation, what others think." Finally, Collective Identity emphasizes the importance of belonging to a collective such as a religious, national, or ethnic group. It contains seven items such as "my race or ethnic background" and "my religion." Participants were asked to rate the importance of each item on a 7-point scale $(1=$ not at all important for the sense of who I am, $7=$ very important for the sense of who I am). Cronbach's alphas have been reported to be .79 to .84 for personal identity, .84 to .86 for social identity, and .68 to .69 for collective identity (Cheek et al., 1994; Dollinger, Preston, O’Brien, \& DiLalla, 1996).

\section{PROCEDURE}

Students completed the identity and demographic questionnaires during sessions that lasted approximately 20 minutes to 30 minutes. They were asked to read the instructions carefully and to answer all questions honestly. It was emphasized that there were no right or wrong answers and that the best answer was their own 
personal opinion. Confidentiality and their anonymity were ensured. The Turkish and White students completed the AIQ and the descriptiveness measures (counterbalanced), whereas the Mexican Americans completed only the AIQ.

\section{RESULTS}

\section{PSYCHOMETRIC PROPERTIES OF QUESTIONNAIRE MEASURES}

The AIQ-IIIx (Cheek et al., 1994), as well as the descriptor ratings measure, showed good internal consistency for our samples, as indicated by the Cronbach alphas in Table 1 . To determine the equivalency of the measures for our samples, we conducted factor analyses. With regard to the $\mathrm{AIQ}$, the confirmatory factor analyses (with varimax rotation) yielded a similar three-factor solution for the three cultural groups, as shown in Table 2. The factors accounted for a somewhat greater proportion of the total variance for the White and Mexican American students than for the Turkish students (as shown in Table 2). Whites and Mexican Americans were also more similar to each other with respect to the relative degree of variance accounted for, with Personal Identity scores showing more systematic individual differentiation than Social and Collective Identity scores. For Turkish students, however, Social Identity showed the most systematic responding compared to the other two identities. One item, "my commitments on political issues or my political activities," loaded negatively for Turkish students under the Collective Identity factor in contrast to the two American samples. Thus, this item was omitted from the Collective Identity factor while computing this factor score for all samples.

In terms of the self-descriptions scale, an exploratory factor analysis yielded a three-factor pattern, with similar results across the White and Turkish samples explaining about $47 \%$ of the total variance in both cultures (see Table 3 ). For both samples, relational interdependence emerged as the first factor. For the Turkish sample, independent and other-focused ratings of the self were approximately equal in the degree of explained variance, whereas for the White sample the other-focused or traditional factor explained somewhat more variance than did the independent factor. One item, "traditional," had a loading less than .30 under this factor for the Turkish sample. In a pooled analysis (including both cultures), 
TABLE 1

Internal Reliabilities (Cronbach's Alphas) for the Attributes of Identity Questionnaire (AIQ) and the Descriptor Ratings Across the Research Samples

\begin{tabular}{|c|c|c|c|}
\hline & \multicolumn{3}{|c|}{ Sample } \\
\hline & Turks $(\mathrm{n}=124)$ & Whites $(\mathrm{n}=135)$ & Mexican Americans $(\mathrm{n}=71)$ \\
\hline \multicolumn{4}{|l|}{ AIQ } \\
\hline Personal & .64 & .91 & .89 \\
\hline Social & .81 & .89 & .79 \\
\hline Collective & .67 & .79 & .78 \\
\hline \multicolumn{4}{|l|}{ Descriptor ratings } \\
\hline Independent & .79 & .77 & \\
\hline Relational & .69 & .61 & \\
\hline $\begin{array}{c}\text { Other-focused o } \\
\text { traditional }\end{array}$ & .62 & .61 & \\
\hline
\end{tabular}

NOTE: The Mexican American sample did not complete the descriptor ratings.

which is conducted to check the commonality of the factors in two cultures, this item had a loading of .43. Thus, although the loading of this item was below .30 for the Turkish sample, we considered it under the other-focused or traditional domain while computing the related self-factor. Conceptually, it is logical to assume that being so-called traditional is consistent with expecting social approval, and being influenced by other's views and thoughts.

\section{CULTURE AND GENDER COMPARISONS}

Importance of identity. For the AIQ ratings of the importance of self-aspects, we conducted a 3 (Students/Culture: Turks, Mexican Americans, Whites $) \times 2$ (Gender $) \times 3$ (Identity: Personal, Social, Collective) ANOVA with repeated measures on the identity factor. The probability level for main effects and interactions was set at $p<.05$. Four significant effects were revealed. All four effects, along with results of planned comparisons or post hoc analyses and related means are depicted in Table 4 . The probability level for post hoc analyses was adjusted, using the Bonferroni method: 18 comparisons for culture $(.05 / 18=.0028)$ and 9 comparisons for gender $(.05 / 9=.0056)$.

First, the type of identity considered most important varied, $F(2$, $648)=258.95, p<.001$. As expected, personal identity was rated as 


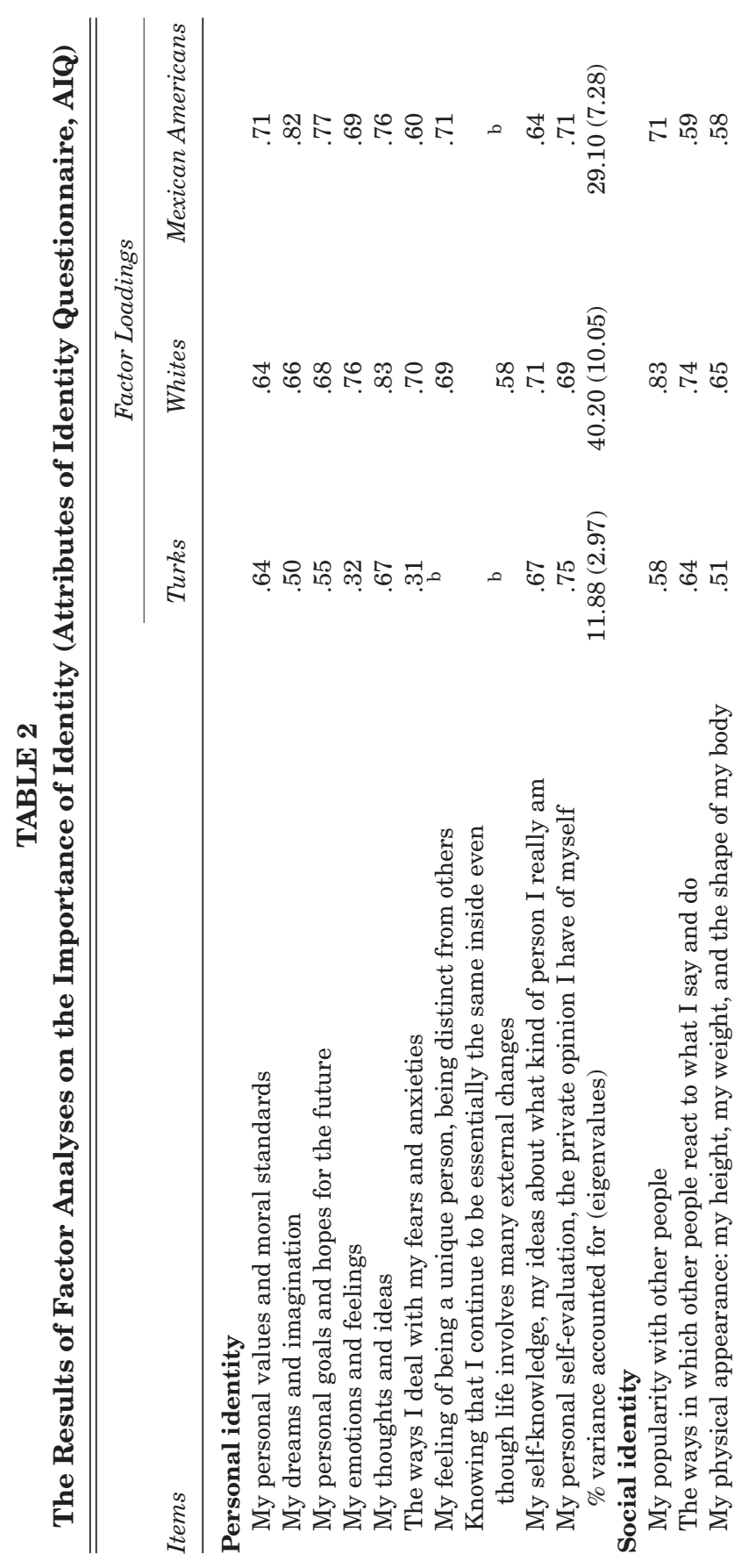




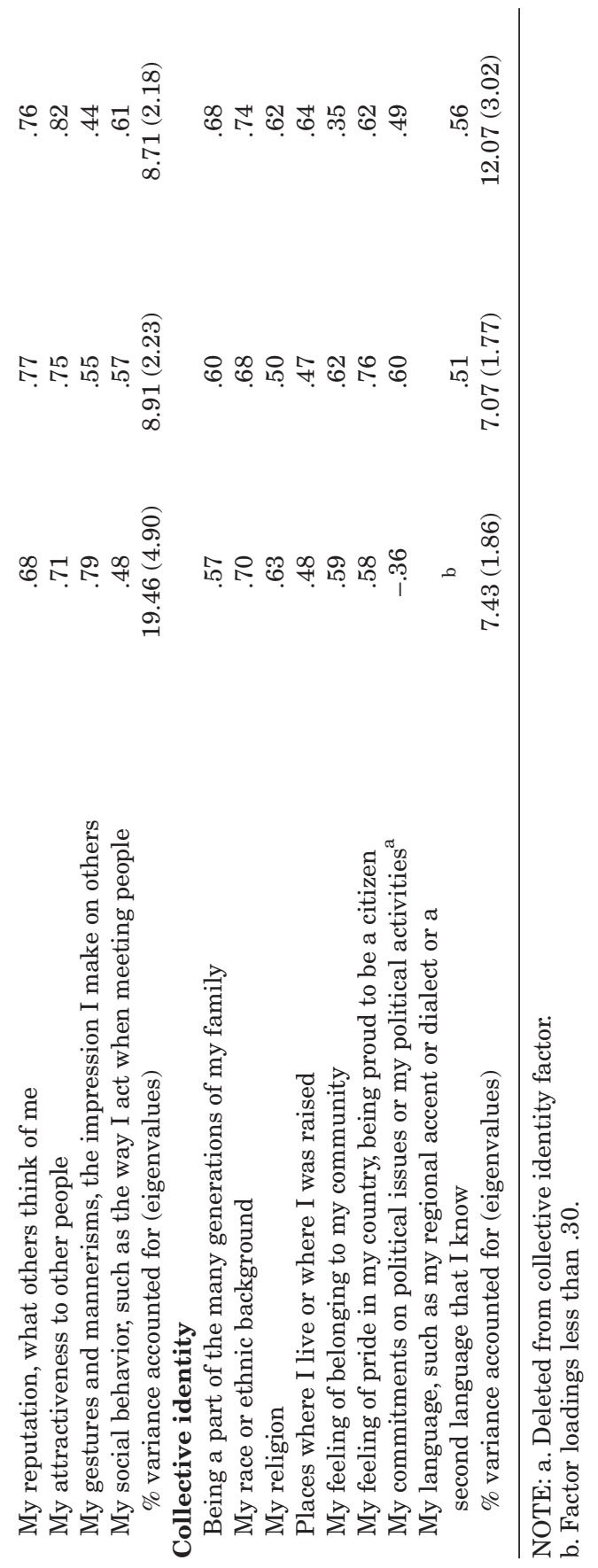


TABLE 3

The Results of Factor Analyses on Descriptiveness of the Self

\begin{tabular}{|c|c|c|}
\hline \multirow[b]{2}{*}{ Items } & \multicolumn{2}{|c|}{ Factor Loadings } \\
\hline & Turks & Whites \\
\hline \multicolumn{3}{|l|}{ Relational descriptiveness } \\
\hline Helpful & .83 & .83 \\
\hline Self-sacrificing & .83 & .61 \\
\hline Sharing & .78 & .79 \\
\hline Friendly & .59 & .68 \\
\hline Trustworthy & .61 & .63 \\
\hline Percent of variance accounted for & 20.75 & 22.20 \\
\hline Eigenvalues & 3.32 & 3.55 \\
\hline \multicolumn{3}{|l|}{ Independent descriptiveness } \\
\hline Creative & .81 & .74 \\
\hline Intelligent & .69 & .57 \\
\hline Different from others & .68 & .33 \\
\hline Humorous & .61 & .74 \\
\hline Curious & .49 & .62 \\
\hline Percentage of variance accounted for & 14.02 & 9.75 \\
\hline Eigenvalues & 2.24 & 1.56 \\
\hline \multicolumn{3}{|l|}{ Other-focused or traditional descriptiveness } \\
\hline Expecting social approval & .80 & .77 \\
\hline Quickly affected by other's views & .66 & .76 \\
\hline Influenced by others in choosing goals & .79 & .55 \\
\hline Emphasizing other's thoughts & .52 & .42 \\
\hline Inflexible in thoughts & .34 & .35 \\
\hline Traditional & $a^{a}$ & .45 \\
\hline Percentage of variance accounted for & 12.85 & 14.71 \\
\hline Eigenvalues & 2.06 & 2.35 \\
\hline
\end{tabular}

NOTE: a. Factor loadings less than .30.

significantly most important, followed by the social identity, which significantly differed in importance from the collective identity. Second, the effect of culture, $F(2,324)=64.23, p<.001$, indicated that Turkish students made more extreme importance ratings than did Mexican Americans, which were more extreme than the ratings of Whites. Third, an interaction between culture and identity importance was obtained, $F(4,648)=4.72, p<.001$. Overall, as expected, the importance ratings of Turkish and Mexican American students were similar to each other across the identity aspects and differed from those of the Whites. In line with Hypothesis 1, the Turkish and Mexican American students rated the social and collective identities as more important than did the Whites. 
TABLE 4

Ratings of the Importance of Identity as a Function of Culture and Gender

\begin{tabular}{lcccc}
\hline \hline & \multicolumn{5}{c}{ Importance of Identity } \\
\cline { 2 - 6 } Sample & $\mathrm{n}$ & Personal M (SD) & Social M (SD) & Collective M (SD) \\
\hline White & 135 & $3.61(.72)_{\mathrm{b}}$ & $2.78(.74)_{\mathrm{d}}$ & $2.52(.76)_{\mathrm{e}}$ \\
Mexican American & 71 & $4.15(.66)_{\mathrm{a}}$ & $3.32(.78)_{\mathrm{c}}$ & $3.32(.86)_{\mathrm{c}}$ \\
Turkish & 124 & $4.23(.40)_{\mathrm{a}}$ & $3.71(.62)_{\mathrm{b}}$ & $3.37(.66)_{\mathrm{c}}$ \\
Women & 203 & $4.04(.65)_{\mathrm{a}}$ & $3.20(.81)_{\mathrm{c}}$ & $2.99(.78)_{\mathrm{d}}$ \\
Men & 127 & $3.84(.70)_{\mathrm{b}}$ & $3.31(.83)_{\mathrm{c}}$ & $3.04(.85)_{\mathrm{d}}$ \\
Column means & & $3.96(.67)_{\mathrm{a}}$ & $3.24(.81)_{\mathrm{b}}$ & $3.01(.85)_{\mathrm{c}}$ \\
\hline
\end{tabular}

NOTE: Ratings are on a 5-point scale, with larger numbers indicating greater importance. Means in columns or rows, within a panel, sharing subscripts do not differ significantly $(p<.0028)$.

Contrary to Hypothesis 2, cultures showed differences between their ratings of the personal identity, with the Turkish and Mexican American students rating this identity as more important than did the Whites. The fourth significant effect was the interaction between importance of identity and gender, $F(4,648)=6.72$, $p<.001$. Again, the personal identity was rated as most important, followed by the social identity, then the collective identity, as previously indicated. Unexpectedly, the difference between women's and men's ratings was for personal identity, which women rated as more important.

Descriptor ratings. For the self-descriptiveness ratings of selfaspects, we conducted a 2 (Students/Culture: Turks, Whites) $\times 2$ (Gender) $\times 3$ (Aspect: Independent, Relational, Other-Focused or Traditional) ANOVA with repeated measures on the self-aspect factor. The probability level for main effects and interactions was set at $p<.05$. Five significant effects were revealed. All five effects, along with results of planned comparisons or post hoc analyses and related means are depicted in Table 5. The probability level for post hoc analyses was adjusted, using the Bonferroni method (9 means for culture and gender: .05/9 = .0058).

First, the self-aspects considered most descriptive varied systematically, $F(2,238)=268.85, p<.001$. Planned comparisons 
TABLE 5

Descriptor Ratings as a Function of Culture and Gender (SD in Parentheses)

\begin{tabular}{lcccc}
\hline \hline & \multicolumn{4}{c}{ Type of Descriptor } \\
\cline { 2 - 5 } Sample & $\mathrm{n}$ & $\begin{array}{c}\text { Independent } \\
\mathrm{M}(\mathrm{SD})\end{array}$ & $\begin{array}{c}\text { Relational } \\
\mathrm{M}(\mathrm{SD})\end{array}$ & $\begin{array}{c}\text { Other-Focused/ } \\
\text { Traditional M (SD) }\end{array}$ \\
\hline White & 117 & $4.34(.77)_{\mathrm{a}}$ & $4.48(.89)_{\mathrm{a}}$ & $2.89(.80)_{\mathrm{d}}$ \\
Turkish & 125 & $3.60(.66)_{\mathrm{c}}$ & $4.03(.67)_{\mathrm{b}}$ & $2.55(.70)_{\mathrm{e}}$ \\
Women & 152 & $3.97(.82)_{\mathrm{b}}$ & $4.42(.77)_{\mathrm{a}}$ & $2.79(.77)_{\mathrm{c}}$ \\
Men & 90 & $3.94\left(.79_{\mathrm{b}}\right.$ & $3.95(.82)_{\mathrm{b}}$ & $2.54(.74)_{\mathrm{d}}$ \\
Column Means & & $3.96(.80)_{\mathrm{b}}$ & $4.25(.82)_{\mathrm{a}}$ & $2.71(.77)_{\mathrm{c}}$ \\
\hline
\end{tabular}

NOTE: Ratings were made on a 7-point scale, with higher ratings indicating that the characteristics were more descriptive. Means in columns or rows, within a panel, sharing subscripts do not differ significantly $(p<.0058)$.

showed that relational traits were rated as most characteristic, followed by independent traits, then finally other-focused or traditional characteristics. Second, the main effect of culture was revealed to be significant, $F(2,238)=53.82, p<.001$. Overall, Whites rated attributes as more descriptive than did Turkish students. These two main effects were qualified by an interaction between self-aspect and culture, $F(4,238)=7.56, p<.001$. Whereas Turkish students made differential ratings across all three selfaspects (relational $>$ independent $>$ other-focused or traditional), the Whites students rated the independent and relational traits as equally descriptive, but more descriptive than the other-focused or traditional descriptions. Contrary to the predictions in Hypotheses 1 and 2, Whites rated the independent and relational traits as more self-descriptive than did the Turkish students.

The fourth effect was the main effect of gender, $F(1,238)=5.74$, $p<.001$, with women making more extreme descriptiveness ratings than men. Finally, there was an interaction between gender and self-aspect, $F(2,476)=7.95, p<.001$. Although women made differential ratings across the three self-aspects (relational $>$ independent $>$ other-focused or traditional), men rated the independent and relational traits as equally descriptive, but more descriptive than the other-focused or traditional descriptors. As expected (Hypothesis 5), women rated the relational and other-focused or traditional descriptors as more self-relevant than did men. 
TABLE 6

Correlations Between Ratings of Importance of Identities and Descriptiveness of Self-Aspects

\begin{tabular}{lcccccc}
\hline \hline & \multicolumn{6}{c}{ Self-Aspects } \\
\cline { 2 - 7 } Self-Aspects & 1 & 2 & 3 & 4 & 5 & 6 \\
\hline 1. Personal identity & & .19 & .16 & .17 & .21 & -.03 \\
2. Social identity & .22 & & $.55^{*}$ & .17 & .13 & $.34^{*}$ \\
3. Collective identity & $.37^{*}$ & $.32^{*}$ & & .01 & .12 & $.33^{*}$ \\
4. Independent descriptiveness & $.25^{*}$ & -.11 & .06 & & .22 & -.09 \\
5. Relational descriptiveness & $.51^{*}$ & .19 & $.34^{*}$ & $.31^{*}$ & & -.05 \\
$\begin{array}{l}\text { 6. Other-focused/traditional } \\
\quad \text { descriptiveness }\end{array}$ & .09 & $.50^{*}$ & .21 & -.11 & .05 & \\
\hline
\end{tabular}

NOTE: Correlations above the diagonal represent the Turkish sample $(n=125)$, whereas correlations below the diagonal represent the White sample $(n=117)$. $* p<.01$.

\section{SELF-SCHEMATIC PROCESSING: RELATION BETWEEN THE IMPORTANCE AND DESCRIPTIVENESS OF SELF-ASPECTS}

To determine the relation between importance and descriptiveness of different conceptualizations of self, we computed Pearson correlations separately for each culture (see Table 6). Given the large number of correlations (15 per culture), we used a conservative probability level ( $p<.01$ ). To provide a context (or ground) for these associations, we first consider the correlations between the three identities and the correlations between the three selfaspects across the two cultures. For the Turkish and U.S. samples, the ratings of importance of the three identities were all positively correlated with each other, with the social and collective identities being significantly associated. The correlations between the descriptiveness ratings of the three self-aspects are remarkably similar for the two cultures, with the descriptiveness of independent and relational characteristics being somewhat correlated; however, the descriptiveness of other-focused/traditional characteristics not being related to descriptiveness of either independent or relational attributes.

We had predicted (Hypothesis 4) that Whites would show schematic (correlated) patterns for the importance of personal identity and independent descriptiveness ratings. As shown in Table 6, this expectation was supported. In addition, as shown in Tables 4 and 5 , the mean ratings for personal identity and independent 
descriptiveness ratings were moderate rather than extreme (with respect to the center of the rating scale). In addition, as expected (Hypothesis 4), Turkish students showed self-schematic patterns of ratings for collective identity and the descriptiveness of otherfocused or traditional self-aspects. Again, mean ratings for identity and descriptiveness were moderate rather than extreme. Unexpectedly, associations between the importance of social identity and the descriptiveness of relational self-aspects were nonsignificant for Turkish students.

We also explored whether women would be more likely to have self-schemas for social or relational self-aspects than would men. In the current study, women and men did not show self-schematic processing for any of the three self-aspects, indicating that culture can be a significantly stronger influence on self-concept than is gender (Dhawan et al., 1995; Driver \& Driver, 1983).

\section{DISCUSSION}

Our cultural groups yielded similarities and differences in their ratings of the importance and descriptiveness of the self. Thus, we found patterns of differences embedded within similarities, which Triandis (1994) cited as requisite for interpreting cross-cultural differences.

\section{CROSS-CULTURAL SIMILARITIES AND DIFFERENCES IN THE IMPORTANCE OF THE SELF}

All of our cultural groups emphasized the personal identity the most, followed by social and collective identity orientations. This finding implies that one's personal thoughts, ideas, values, sense of uniqueness, and feelings of being distinct from others seem to be the most important aspect of the self regardless of culture. Our results with respect to the importance of personal identity challenge previous theories on individualism-collectivism (Markus \& Kitayama, 1991; Triandis, 1989, 1994). The results, however, are in line with more recent contentions of Matsumoto (1999) that the individualism-collectivism models of Markus and Kitayama (1991) and Triandis $(1989,1994)$ have not received substantive support in rigorous empirical tests. Moreover, Matsumoto provided evidence from dozens of studies showing that Japanese have 
often scored lower on collectivism and higher on individualism than Americans (see Matsumoto, 1999, for a review). Matsumoto explained this "unexpected" pattern as being due to cultural change in Japan. This may also be the case for our student samples.

With regard to existing differences across cultural groups, the results supported our hypotheses. The importance ratings of Turkish and Mexican American students were similar to each other across the identity orientations and differed from the ratings of Whites. Turkish and Mexican American students emphasized the importance of social and collective identity more than did Whites. We expected this pattern, as self-concept develops in an environment where group memberships and other-orientedness are emphasized in these particular sociocultural contexts. The greater emphasis on personal aspects of the self by Turkish and Mexican American students in contrast to Whites was somewhat surprising, however, and inconsistent with previous research (Cheek et al., 1994; Hofstede, 1980; Trafimow \& Finlay, 2001). A tentative explanation for the greater emphasis on personal identity among Turkish and Mexican American students than their White counterparts may lie in the attributes of the student samples. For Turkish and Mexican American students, individualism and collectivism present contrasting value systems in their everyday lives. The majority of these students may have been raised to prioritize an interdependent value system, such that this aspect of self seems more natural or automatic. Given the university context, however, they may be attempting to develop this personal aspect of themselves, such that this aspect is highly salient. White students may have already had the opportunity to develop this aspect of self, such that its importance is not so highly salient. Future research could directly assess this speculation.

The identity orientation that showed the greatest differentiation across the three cultural groups was social identity. Turkish students emphasized it the most, followed by Mexican Americans, then by White students. The difference among Turkish and Mexican American students may be explained by Mexican Americans' upbringing in the individualistic American culture. Although they are expected to attend to their influence on others, as well as others' influence on them, still they may be less concerned with their reputation and impression on others as compared to Turkish students who are still subject to social influences even in individualistic urban metropolitan areas. Whites, on the other hand, as 
hypothesized, tended to show less concern with the effects of their social behaviors on others, in line with their individualistic upbringing as compared to other two samples.

\section{CROSS-CULTURAL SIMILARITIES AND DIFFERENCES IN THE DESCRIPTIVENESS OF THE SELF}

Across cultures, relational traits were rated as highly descriptive of the self and other-focused or traditional characteristics as the least descriptive. This similarity across the two cultures, first, points to importance and universality of human relatedness. Actually, several theorists (Baumeister \& Leary, 1995; Tice \& Baumeister, 2001) have argued that the need for belongingness is one of the powerful and fundamental human motivations that have positive effects on health, adjustment, and well-being. Second, our findings refer to the fact that items endorsing rigid normative expectations and items constraining personal interests and autonomy tend to be perceived less self-descriptive in both cultures. These findings are supportive of theoretical models in the literature that conceptualize independence and relatedness as two basic needs and pathways in life. Theoretical formulations (e.g., individuality and relatedness, Guisinger \& Blatt, 1994; individuational and interrelational self-development, Imamoğlu, 1998; agency and interpersonal distance, Kaḡitçıbașı, 1996a) have considered these two orientations as complementary rather than contradictory. Thus, our findings contribute to the literature by showing that (a) independent and relational and other-focused themes seem to coexist within the same individual across cultures and (b) independent, relational themes tend to be perceived as more selfdescriptive than the other-focused or traditional themes regardless of culture.

With regard to differences in the descriptiveness ratings across cultures, the results partially supported our hypotheses. As hypothesized, White respondents found the independent items to be more self-descriptive of the self than did Turkish respondents. However, the greater descriptiveness of relational and otherfocused items among White than Turkish students is interesting. Actually, Cross et al. (2000) provided support for the existence of relationality in the United States and argued that the common modality of interdependence in the United States is relational rather than group oriented. In such an individualistic environment, 
where interpersonal distance is emphasized, people may seek more close relationships and experiences with others in line with their universal need for relatedness and belongingness. Moreover, our Turkish students live in an environment where relationships are strongly emphasized (Kağıtçıbașı, 1990, 1996b). In line with recent trends toward individualism and independence, they may be reacting to social expectations emphasizing fused relationships and behaving in accordance with others' expectations, which probably led to less endorsement of relational and other-focused or traditional items in the current study. Alternatively, Turkish students may be less willing to "claim" traits as their own, compared to White students. Research has shown that people from collectivist cultures are less likely to describe themselves using traits than are individualists (Cousins, 1989), unless the traits are expressed within context (e.g., at school). Clearly, additional cross-cultural investigations are needed to address this issue.

Methodologically, the patterns of descriptiveness and importance ratings of Turkish and White students indicate that the differences are not due to cultural response biases; that is, the fact that Turkish students made higher importance ratings and White students made higher descriptiveness ratings argues against either cultural group having an acquiescence bias, for example. Moreover, the differential patterns indicate that perceived importance and descriptiveness of self-aspects do not necessarily coincide in individuals. Thus, the current results imply that importance and descriptiveness must be considered when determining whether a person is self-schematic for any given characteristic.

\section{GENDER DIFFERENCES IN THE DESCRIPTIVENESS AND IMPORTANCE OF SELF}

Supporting our hypothesis, women were found to be more relational and other-focused or traditional as compared to men in the descriptiveness ratings. These results are consistent with previous research, which illustrates that women are more likely to have more interdependent and relational self-construals (see Cross \& Madson, 1997, for a review; Gabriel \& Gardner, 1999; Gilligan, 1982). Those results imply that women tend to be more open than men to influences from others in relationships and be easily swayed by opinions and decisions of other people with whom they are in frequent contact. 
Unexpectedly, we found that women attributed more importance to personal identity than did men, although there were no gender differences in ratings of the independent descriptors of the self. This finding also supports the distinction between the dimensions of importance and descriptiveness of self-aspects. It is quite clear that, given the fact that women are expected to be relational, interdependent, and sensitive to others, they find it very important to be autonomous and to emphasize personal feelings, thoughts, and interests. The greater importance of personal identity among women than men may also be explained by sample characteristics. Pursuing a university degree may require emphasizing the personal aspects of the self to be able to achieve and survive in an individualistic competitive environment for women.

\section{THE RELATIONSHIPS BETWEEN DESCRIPTIVENESS AND THE IMPORTANCE OF THE SELF}

We examined correlations between descriptiveness and importance ratings separately for each culture to ascertain whether selfschematic processing differs across cultures. Self-schematic processing was defined in terms of strong positive correlations between importance and descriptiveness ratings for a particular self-aspect (i.e., personal or independent, social or relational, collective or other focused), coinciding with moderate mean ratings of these aspects. As predicted, we found the more collectivist Turkish students to show variations in their collective or other-focused selfaspects, whereas White students varied in self-schematic ratings for the personal or independent dimension of self-concept. These patterns indicate that importance and descriptiveness of culturally "mandated" self-aspects are likely to covary across individuals. Unexpectedly, correlations between social or relational importance and descriptiveness did not systematically covary for either culture. This finding can be explained by somewhat differential focus of the two scales. The Social Identity scale measures the importance of social roles, behaviors, and impression on others, whereas the relational descriptiveness measures the interpersonal aspects of the self that play an important role in maintaining relationships with others. Rather, social identity was closely related to other-focused or traditional descriptiveness in both cultures. Those results imply that individuals emphasizing the social implications of their behaviors and reputation on others seem to be 
concerned with other orientedness and being influenced by opinions of others. With respect to gender patterns, neither the male or female students, as a group, showed self-schematicity for any of the three domains of self-aspects. This finding supports previous work (Dhawan et al., 1995; Driver \& Driver, 1983) showing that cultural patterns related to the self-concept may be stronger than gender patterns.

In conclusion, the current study contributed to the field in two ways. First, it examined descriptiveness and importance of the self across different cultures and genders. To date, studies more often examined only the descriptiveness of the self as a function of culture and gender. They rarely studied importance ratings (Cheek et al., 1994; Trafimow \& Finlay, 2001). Studying descriptiveness and importance may provide a better understanding of the self across cultures and genders. As a matter of fact, our findings illustrated that although there are some similarities in the overall pattern of descriptiveness and importance across cultures, importance and descriptiveness ratings do not show the same pattern in different cultural groups or across gender groups. Therefore, the current results suggest that descriptiveness and importance ratings should not be considered equivalent. Second, the current research showed that a sample from a collectivist culture, Turkey, may not be necessarily exhibit the patterns that some theorists (Markus \& Kitayama, 1991; Triandis, 1994) have proposed. Hence, our results suggest that researchers should pay attention to importance and descriptiveness of self and to sample characteristics while examining the self within a cross-cultural perspective.

\section{Notes}

1. Some preliminary research on the importance as self-aspects has been conducted in the United States, however, comparing various ethnicities (Cheek, Tropp, Chen, \& Underwood, 1994; Trafimow \& Finlay, 2001).

2 . These two types of self-descriptions also tend to coincide with two of the Big 5 personality factors, the independent attributes indicating Openness and the interdependent attributes indicating Agreeableness. We thank an anonymous reviewer for offering this interpretation. 


\section{References}

Baumeister, R. F., \& Leary, M. R. (1995). The need to belong: Desire for interpersonal attachments as a fundamental human motivation. Psychological Bulletin, 117, 497-529.

Bochner, S. (1994). Cross-cultural differences in the self-concept: A test of Hofstede's individualism/collectivism distinction. Journal of CrossCultural Psychology, 25, 273-283.

Bond, M. H., \& Cheung, T. S. (1983). College students' spontaneous selfconcept: The effect of culture among respondents in Hong Kong, Japan, and the United States. Journal of Cross-Cultural Psychology, 14, 153171.

Brewer, M. B., \& Gardner, W. (1996). Who is this "we"? Levels of collective identity and self representations. Journal of Personality and Social Psychology, 71, 83-93.

Carpenter, S. (1988). Self-relevance and goal-directed processing in the recall and weighting of information about others. Journal of Experimental Social Psychology, 24, 310-332.

Cheek, J. (1989). Identity orientations and self-interpretation. In D. M. Buss \& N. Cantor (Eds.), Personality psychology: Recent trends and emerging directions (pp. 275-285). New York: Springer-Verlag.

Cheek, J. M., Tropp, L. R., Chen, L. C., \& Underwood, M. K. (1994, August). Identity orientations: Personal, social and collective aspects of identity. Paper presented at the meeting of the American Psychological Association, Los Angeles, CA.

Çileli, M. (2000). Change in value orientations of Turkish youth from 1989 to 1995. Journal of Psychology, 134, 297-305.

Cousins, S. D. (1989). Culture and self-perception in Japan and the United States. Journal of Personality and Social Psychology, 56, 124-131.

Cross, S. E., Bacon, P. L., \& Morris, M. L. (2000) The relational-interdependent self-construal and relationships. Journal of Personality and Social Psychology, 78, 791-808.

Cross, S. E., \& Madson, L. (1997). Models of the self: Self-construals and gender. Psychological Bulletin, 122, 5-37.

Dhawan, N., Roseman, R. J., Naidu, R. K., Thapa, K., \& Rettek, S. I. (1995). Self-concepts across two cultures: India and the United States. Journal of Cross-Cultural Psychology, 26, 606-621.

Diaz-Loving, R., \& Draguns, J. G. (1999). Culture, meaning, and personality in Mexico and the United States. In C. Kimble, E. Hirt, R. Diaz-Loving, H. Hosch, G. W. Lucker, et al. (Eds.), Personality and person perception across cultures (pp. 103-126). Mahwah, NJ: Lawrence Erlbaum.

Dollinger, S. J., Preston, L. A., O’Brien, S. P., \& DiLalla, D. L. (1996). Individuality and relatedness of the self: An autophotographic study. Journal of Personality and Social Psychology, 71, 1268-1278.

Driver, E. D., \& Driver, A. E. (1983). Gender, society, and self-conceptions: India, Iran, Trinidad-Tobago, and the United States. International Journal of Comparative Sociology, 24, 200-217.

Fiske, S. T., \& Taylor, S. E. (1991). Social cognition. New York: McGraw-Hill. 
Fișek, G. O. (1984). Psychopathology and the Turkish family: A family systems theory analysis. In Ç. Kağıtçıbașı (Ed.), Sex roles, family and community in Turkey (pp. 295-321). Bloomington: Indiana University Press.

Gabriel, S., \& Gardner, W. L. (1999). Are there "his" and "hers" types of interdependence? The implications of gender differences in collective versus relational interdependence for affect, behavior, and cognition. Journal of Personality and Social Psychology, 77, 642-655.

Gaines, S. O. Jr., Marelich, W. D., Bledsoe, K. L., Steers, W. N., Henderson, M. C., Granrose, C. S., et al. (1997). Links between race/ethnicity and cultural values as mediated by racial/ethnic identity and moderated by gender. Journal of Personality and Social Psychology, 72, 1460-1476.

Gilligan, C. (1982). In a different voice: Psychological theory and women's development. Cambridge, MA: Harvard University Press.

Göregenli, M. (1997). Individualist and collectivist tendencies in a Turkish sample. Journal of Cross-Cultural Psychology, 28, 787-793.

Guisinger, S., \& Blatt, S. J. (1994). Individuality and relatedness: Evolution of a fundamental dialectic. American Psychologist, 49, 104-111.

Güneri, O., Sümer, Z., \& Yıldırım, A. (1999). Sources of self-identity among Turkish adolescents. Adolescence, 34, 535-546.

Hofstede, G. (1980). Culture's consequences: Comparing values, behaviors, institutions, and organizations across nations (2nd ed.). Thousand Oaks, CA: Sage.

Imamoğlu, E. O. (1987). An interdependence model of human development. In Ç. Kağitçıbaș (Ed.). Growth and progress in cross-cultural psychology (pp. 138-145). Lisse, The Netherlands: Swets \& Zeitlinger.

Imamoglu, E. O. (1998). Individualism and collectivism in a model and scale of balanced differentiation and integration. Journal of Psychology, 132, 95-105.

Imamoḡlu, E. O., \& Karakitapoḡlu-Aygün, Z. (1999). 1970lerden 1990lara degerler: Üniversite düzeyinde gözlenen zaman, kuşak ve cinsiyet farklilıkları [Value preferences from 1970s to 1990s: Cohort, generation and gender differences at a Turkish university]. Türk Psikoloji Dergisi, 14(44), 1-22.

Ip, G. W. M., \& Bond, M. H. (1995). Culture, values and the spontaneous self-concept. Asian Journal of Psychology, 1, 29-35.

Kağitçıbașı, C.. (1990). Family and socialization in cross-cultural perspective: A model of change. In J. Berman (Ed.), Cross-cultural perspectives: Nebraska symposium on motivation 1989 (pp. 135-200). Lincoln: University of Nebraska Press.

Kağıtçıbașı, Ç. (1996a). The autonomous-relational self: A new synthesis. European Psychologist, 1, 180-186.

Kağıtçıbașı, Ç. (1996b). Family and human development across cultures: A view from other side. Mahwah, NJ: Lawrence Erlbaum.

Karadayı, F. (1998). Ilișkili özerklik: Kavramı, ölcülmesi, gelișimi ve toplumsal önemi, gençlere ve kültüre özgü degerlendirmeler [Related autonomy: Its concept; measurement, development, and societal importance]. Adana, Turkey: Çukurova Üniversitesi Basımevi .

Karakitapoḡlu-Aygün, Z., \& Imamoḡlu, E. O. (2002). Value domains of Turkish adults and university students. Journal of Social Psychology, 142, 333-351. 
Karakitapoḡlu-Aygün, Z. (2004). Self, identity and well-being among Turkish university students. Journal of Psychology, 138(5), 457-478.

Kashima, E. S., \& Hardie, E. A. (2000). The development and validation of the relational, individual and collective self-aspects scale. Asian Journal of Social Psychology, 3, 19-48.

Kashima, Y., Kashima, E., \& Aldridge, J. (2001). Toward cultural dynamics of self-conceptions. In C. Sedikides \& M. B. Brewer (Eds.), Individual self, relational self, collective self (pp. 277-298). Philadelphia: Psychology Press.

Kashima, Y., Kim, U., Gelfand, M. J., Yamaguchi, K. Y., Choi, S. C., \& Yuki, M. (1995). Culture, gender and self: A perspective from individualismcollectivism research. Journal of Personality and Social Psychology, 69, 925-937.

Lykes, M. B. (1985). Gender and individualistic versus collectivist bases for notions about the self. Journal of Personality, 53, 357-383.

Markus, H. (1977). Self-schemas and processing information about the self. Journal of Personality and Social Psychology, 35, 63-78.

Markus, H. R., \& Kitayama, S. (1991). Culture and the self: Implications for cognition, emotion and motivation. Psychological Review, 98, 224253.

Matsumoto, D. (1999). Culture and self: An empirical assessment of Markus and Kitayama's theory of independent and interdependent self-construals. Asian Journal of Social Psychology, 2, 289-310.

Oyserman, D. (1993). The lens of personhood: Viewing the self and others in a multicultural society. Journal of Personality and Social Psychology, 65, 993-1009.

Oyserman, D., Coon, H. M., \& Kemmelmeier, M. (2002). Rethinking individualism and collectivism: Evaluation of theoretical assumptions and meta-analyses. Psychological Bulletin, 128, 3-72.

Rhee, E., Uleman, J. S., Lee, H. K., \& Roman, R. J. (1995). Spontaneous selfdescriptions and ethnic identities in individualistic and collectivistic cultures. Journal of Personality and Social Psychology, 69, 142-152.

Sedikides, C., \& Brewer, M. B. (2001). Individual self, relational self and collective self: Partners, opponents, or strangers. In C. Sedikides \& M. B. Brewer (Eds.), Individual self, relational self, collective self (pp. 1-4). Philadelphia: Psychology Press.

Singelis, T. M. (1994). The measurement of independent and interdependent self-construals. Personality and Social Psychology Bulletin, 20, 580-591.

Tice, D. M., \& Baumeister, R. F. (2001). The primacy of the interpersonal self. In C. Sedikides \& M. B. Brewer (Eds.), Individual self, relational self, collective self (pp. 71-89). Philadelphia: Psychology Press.

Trafimow, D., \& Finlay, K. A. (2001). The importance of traits and group memberships. European Journal of Social Psychology, 31, 37-43.

Triandis, H. C. (1989). The self and social behavior in differing cultural contexts. Psychological Review, 96, 506-520.

Triandis, H. C. (1994). Culture and social behavior. New York: McGraw-Hill.

Triandis, H. C., Marín, G., Lisansky, J., \& Betancourt, H. (1984). Simpatía as a cultural script of Hispanics. Journal of Personality and Social Psychology, 47, 1363-1375. 
Uleman, J., Rhee, E., Bardoliwalla, N., Semin, G., \& Toyama, M. (2000). The relational self: Closeness to ingroups depends on who they are, culture and the type of closeness. Asian Journal of Social Psychology, 3, 1-17.

Vandello, J. A., \& Cohen, D. (1999). Patterns of individualism and collectivism across the United States. Journal of Personality and Social Psychology, 77, 279-292.

Watkins, D., Adair, J., Akande, A., Gerong, A., McIerney, D., Sunar, D., et al. (1998). Individualism-collectivism, gender, and the self-concept: A nine culture investigation. Psychologia, 41, 259-271.

Watkins, D., Mortazavi, S., \& Trofimova, I. (2000). Independent and interdependent conceptions of self: An investigation of age, gender, and culture differences in importance and satisfaction ratings. Cross-Cultural Research, 34, 113-134.

Sandra Carpenter is professor and chair of the Department of Psychology at The University of Alabama in Huntsville. She received her Ph.D. from the University of California in Santa Barbara. Her research focuses on cross-cultural conceptions of self and on cognitive representations of the self (self-schematicity), in-groups and out-groups. She has also conducted research on the categorization of gender information. She met Zahide Karakitapoḡlu-Aygün, her coauthor, at a meeting of the Society for CrossCultural Research (SCCR).

Zahide Karakitapoḡlu-Aygün is an assistant professor at Bilkent University, Faculty of Business Administration, Ankara, Turkey. She has a Ph.D. in social psychology from Middle East Technical University. Her research interests include self-conceptions, cultural values, and organizational behavior. 